\title{
Quantified Observations of Sensory Processing (QOSP): Resource Tool for Screening Sensory Processing Difficulties in Preschoolers
}

\author{
Moushami S. Kadkol
}

Seth G.S. Medical College, Mumbai, India

\begin{abstract}
Sensory Processing (SP) difficulties in children are seen to be increasing in today's world. Quite a few typically developing children are reported to have difficulties in coping with school, home and play environments. Their difficulties are mostly labeled abnormal behaviors and with superficial assessments these children often receive traditional treatments that marginally decrease their problems without giving long term functional gains. Hence their SP dysfunctions make them adopt pathological behaviors as they grow, making them incompetent as compared to their peers.

One of the factors behind these children getting unnoticed at an early age is lack of awareness about SP difficulties among the parents, teachers and medical fraternity in India. The other important factors include unavailability of contributory study in this area done on the Indian population and the use of non-normated, generalized evaluation tools done for evaluation of these difficulties. Further less information on what is age related typical SP makes it trickier to differentiate between a typical behavior and SP difficulty. The present study is the first study that would make an effort to understand the age related SP in Indian preschoolers aged 3-7 years.

The QOSP includes observations based on literature and theoretical constructs of SP which are graded and made quantitative for ease of administration and interpretation. This study intends to establish the age appropriate expected response and estimate the children posing risk to develop SP dysfunctions. The study further attempts to understand correlations between the different parameters of QOSP and tries to identify those parameters that can be considered red flags for SP difficulties.

The results of the study suggest about $3 \%$ of children in the typically developing group to be at the risk of having SP difficulties. About $20 \%$ are estimated to be having difficulties in at least one of the SP areas when compared with behaviors rated on Sensory Processing Measure. Apart from typically developing children the tool was also used in comorbid conditions and was found to be useful in understanding the underlying Sensory Processing difficulties. Thus the QOSP can be considered a good measure not only in screening children with suspected sensory processing difficulties but also to gear the intervention program to be streamlined and goal oriented.
\end{abstract}

Keywords: Rehabilitation personnel, Sensory Processing Measure, Sensory systems, Play, Behavior disorders.

Sensory processing (SP) lays the foundation for well-developed functioning of the behavioral and performance components of a human being (Ayres, 1969) [1]. SP occurs through our regular experiences associated with our interactions with the environment, and our perception of it (Lane, 2002) [2]. It also refers to the management of incoming sensory information by both, the peripheral and central nervous system.

SP involves a neurological process and depends on the sensations conveyed by the sensory systems. The sensory systems include tactile (touch), vestibular (situated in the ear), proprioceptive (inputs from joints and muscles) [2, 3]. The information from our surroundings or environment reaches the brain that is our processing centre through various sensations conveyed through the receptors of these systems. In our regular experiences of self and environment, as multiple sensory information impinges upon the brain, a finely-tuned filter system is activated. The sensory input

*Address correspondence to this author at the Seth G.S. Medical College, 113, Saraswati Niwas, Hindu Colony, Road No.4, Dadar, Mumbai- 400014, India; Te: 91-22-24145569, +919820528831; E-mail: moushamikadkol@gmail.com that is pertinent to the learner's inner needs and goals reaches the level of consciousness.

$\mathrm{SP}$ involves modulation and discrimination of sensory inputs as main processes. Various studies (Luna et al., 2005; Kringelbach, 2005) involving human primates and humans have found the structural correlates of sensory experiences in the brain stem (including the midbrain, pons, and medulla oblongata), thalamus and the somato sensory cortex $[4,5]$.

The sensory systems closely aligned with the SP Theory are Somato Sensory that includes tactile (touch) and proprioception (inputs from joints and muscles), Vestibulo (in the ear) - Proprioceptive, and Visual alongwith complex interplay of the processes involving the limbic system, reticular formation, and the cerebral cortex (Lane, 2010, Shriber, 2008) [6, 7].

The importance and role of SP has been documented since the very early stages of development of the child. Early sensory experiences enrich the development of the brain to make it ready to adapt to the changes in the environment also known as experience dependent plasticity. As the child grows, SP 
skills become enhanced due to the increased involvement, engagement, and participation of the child in his environment; be it at home, school, or during play $[2,3,8]$.

Sensory Processing difficulties in infancy are termed as "regulatory disorders". Infants with sensory processing difficulties have difficulty processing many environmental and internal inputs and may appear confused with their body position and movement.

During toddlerhood when typically skill acquisition takes place and higher coordination starts developing, children with affected sensory processing struggle with their movements, coordinated actions and transitions.

Sensory Processing Difficulties (SPD) is a distinct diagnosis on basis of neuroimaging where different areas of the brain are affected than those in other diagnoses (Owen et al., 2013) [9]. Nevertheless, SPD are often confused with other diagnoses like Attention Deficit Hyperactivity Disorders, Autism Spectrum Disorders and Pervasive Developmental Disorders that require management with medication along with remedial and conventional therapy. All these conditions have significantly more sensory, attention, activity, impulsivity, and emotional difficulties than typical children, but with distinct evaluation profiles.

It is estimated that about $10-22 \%$ of children in the US have enough problems in one or more areas of SP (Ahn et al., 2004, Ben-Sasson et al., 2009) that cause them to be slow learners, have specific learning disabilities, experience incompetence in academic and lifestyle skills, or suffer behavioral problems [10, 11]. If early intervention is not undertaken, then, by the time the child seeks help, he has lost his years of innocence, play, and development (Roley, 2001) [3].

Studies undertaken by Miller et al. (2007), Dobbins (2007), Schoen (2009) and Lane (2010) on modulatory and discriminatory difficulties of SP have revealed their links to various conditions like ADHD, LD, Autism, Fragile $X$ syndrome, and their phenotypes [7, 12-14].

When children with probable sensory processing difficulties or exhibiting behaviors resembling them are referred for evaluation and intervention in Occupational Therapy Clinic, they are evaluated with the use of parental questionnaires, random tests to observe gross and fine motor difficulties or visuomotor tests. The SIPT test that assesses sensory integration is standardized for the US population for specific ages, is exhaustive and requires interpretation skills. Other tests that are used include subtests of motor performance tests, nonstandardized clinical observations and some neurological soft signs (Bagchi 1996, Blanche 2008, Patankar, 2012) [15-17]. Therapeutic intervention with such partial evaluations provide marginal relief from the difficulties but the child still struggles to maintain himself with his ever changing and challenging environment. Eventually the child begins to cope with his SP difficulties at the cost of play, sport, and life skills.

Also evaluation by these means is reported to be ambiguous by some studies (Owen, 2013) and lack age appropriate, observational and response guidelines [9]. Furthermore the literature did not yield any results for prevalence of these disorders in different parts of the globe.

A structured, specific system pertinent tool derived from the existing clinical observations and constructs would address SP in the Indian population; its function and aberration. This would help to reduce the randomness of therapy. Hence the present study was carried out with the objectives of:

1. Identifying the nature of Sensory Processing in children aged between 3 and 7 years in crosssectional Indian population

a. Itemizing and grading the parameters to ease the process of administering or collecting data

b. Validating the newly developed tool of Quantified Observations of Sensory Processing (QOSP) in Indian children (aged 3-7 years).

c. To comment and compare Sensory Processing Measure (SPM) and QOSP observations

d. Apply the QOSP on a patient population with various diagnoses like ADHD, Autism, and Developmental disorders

2. Find the correlation between various parameters of the QOSP.

a. Identify the relevant cluster of clinical signs that can be treated as red flags for concern.

3. Comment on the prevalence of SP difficulties in Indian children of 3-7 years of age 
a. Finding the reference range of the QOSP

b. Estimating the prevalence of sensory processing difficulties in the typically developing population in the specified age group on the basis of reference range achieved.

Literature review of Sensory Processing [18-24]:

Dr. Ayre's (1969) conceptualized the theory and worked towards developing the constructs of sensory processing with a neurophysiologic basis. Her research suggested that sensory processing involves the conceptualization, planning and execution of skilled adaptive interaction for which somatosensory, visual and vestibular sensory inputs are essential. Studies on animal models, infants, children and adults suggest sensory experiences exert many positive effects on the brain like increase in number and size of synapses per neuron, neuronal activity and change in the metabolic demands and vascular network of the brain. Sensory experiences have been found to increase exploratory activity, memory and learning and have long term pertinent benefits triggering brain plasticity and neuronal reorganization. The primary and secondary somatosensory cortices have shown neural correlates to sensory processing. Recent studies provide evidence of white matter abnormalities in the parietal and occipital tracts differentiating Sensory Processing Disorders from comorbidities like ADHD. Sensory processing and integration that happens through play has been thought to improve coping skills, problem solving abilities, language and social development.

\section{METHODOLOGY}

A random independent sample of 302 children was collected using the Universal Sampling Technique over a period of one year from the Mumbai-based suburban schools. The children were included randomly irrespective of the board affiliations, medium of instruction, caste, creed, race and socio-economic conditions. The parents consent was obtained before evaluating the child. As this was a new endeavour the school authorities and parents were given an understanding about the topic and the research objective. The sample included typically developing children in the age group of 3-7 years not diagnosed with any physical, intellectual or cognitive dysfunction. The resource tool was developed from the Clinical observations of Sensory integration and was named Quantitative Observations of Sensory Processing
(QOSP). QOSP observes for responses on various tests developed for evaluation of different sensory systems like somatosensory (tactile and proprioceptive), vestibulo-proprioceptive and visuovestibular. The QOSP was validated by experts in related areas like neurology, psychiatry and occupational therapy and administered on a pilot sample $(n=20$, Mean age 4.34 years, $S D \pm 1.25)$ to examine reliability and feasibility. The internal consistency of all the items of the tool were assessed using Cronbach's alpha. Cronbach's alpha is widely believed to indirectly indicate the degree to which a set of items measures the same construct. It is also believed to be an unbiased estimate of the generalizability. As the pilot sample indicated statistically significant reliability (Cronbach's alpha > 0.8 ), the resource tool was considered to have domain homogeneity and consistency. The response to QOSP parameters was observed and described qualitatively. They were graded with 0 or 1 grade to make them quantitative for scoring. Grade 1 was awarded if the observation matched to the expected response mentioned in literature. Grade 0 indicated unmatched response to Grade 1. In this process an attempt was made to understand the expected responses at different ages so that limitations could be differentiated from aberrations. The QOSP were evaluated using the following guidelines (Griesemer's approach) [25]:

1. The child was shown the movement to be performed during the evaluation and made to understand how to perform it himself.

2. The child was allowed to practice for 2-3 repetitions after which he was graded.

3. The child who scored 0 on a parameter needed to have a special remark in terms of the observations commenting on deviation from expected response wherever appropriate.

Table 1 shows the QOSP parameters along with the system they theoretically and conceptually evaluate.

The children were also graded on the School based version of the Sensory Processing Measure (SPM) questionnaire to understand the QOSP better. The teacher of the participant (child) answered the questions in the light of the behaviour of the participant. The SPM comments were related to the behaviour of the child observed for a month. SPM has standardized scores indicating probable, typical and some affectations of sensory processing. It is a questionnaire 
Table 1: QOSP and Sensory Systems

\begin{tabular}{|c|c|}
\hline Parameter & Sensory System \\
\hline QOSP 1 Diadokokinesis & SSP \\
\hline QOSP 2 Sequential Finger Touching & SSP \\
\hline QOSP 3 Finger Nose Test & SSP \\
\hline QOSP 4 Anti Gravity Flexion & SSP \\
\hline QOSP 5 Schilder's Arm Extension & VPP \\
\hline QOSP 6 Anti Gravity Extension & VPP \\
\hline QOSP 7 Postural Control & VPP \\
\hline QOSP 8 Protective Extension & VPP \\
\hline QOSP 9 Weight Bearing & VPP \\
\hline QOSP 10 Gravitational Insecurity & VP \\
\hline QOSP 11 Projected Action Sequences & VPP \\
\hline QOSP 12 Bilateral Motor Coordination & VPP \\
\hline QOSP 13 Reaction to Vestibular Sensations & VPP \\
\hline QOSP 14 Reaction to Tactile Sensations & SSP \\
\hline QOSP 15 Free Play and Play Preferences & SSP, VPP, VVP \\
\hline QOSP 16 Praxis & SSP, VPP, VVP \\
\hline QOSP 17 Conscious Eye Movements & VVP \\
\hline QOSP 18 Automatic Eye Movements & VVP \\
\hline
\end{tabular}

Somato Sensory Processing (SSP), Vestibulo-Proprioceptive Processing (VPP) and Visuo-Vestibular Processing (VVP).

enquiring about the behaviour of the child in different situations classified under social participation, visual processing, oro- motor processing, balance and coordination, motor planning and praxis which are scored on how frequently these may be observed. The frequency of each observation is graded numerically and a standard score is obtained which denotes the quality of affectation, whether there exist definite or some problems in sensory processing or the child is typical in sensory processing.

For the purpose of data triangulation, a sample of 38 children diagnosed with various conditions like Learning Disorders, Pervasive Developmental Disorders, Attention Deficit Hyperactive Disorder (ADHD), Attention Deficit Disorder (ADD) and Behavioural Disorders was evaluated using the Quantified Structured Clinical Observations. This sample was statistically analyzed to compare with the reference scores of QOSP for the typical population and arrive at a cut off limit of scores of the observations in co-morbid populations.

\section{RESULTS AND DISCUSSION}

QOSP was administered on a sample of 302 typically developing children, 150 boys and 152 girls, in the age group of 3-7years (Mean age $=5.15$ years, SD $= \pm 1.09$ ). The children were divided in to two age groups: Group 1included 151 children between 3 to 5 years $(73$ boys, 78 girls, Mean age $=4.25$ years, SD $=$ \pm 0.65 ) and Group 2 included 151 children between 5.1 to 7 years ( 77 boys, 74 girls, Mean age $=6.05$ years, $\mathrm{SD}= \pm 0.58$ ). This was done to understand and note for any age related difference in response. The response observed in majority for each of the parameters was considered the expected response of typically developing children. Table 2 shows the percentage of children in both the groups grading 1 on the response.

It was seen that although the theoretically expected responses on QOSP parameters were obtained in Group 2 children, the responses of Group 1 children differed for some parameters. Hence for QOSP 2 and 6 theoretical responses should not be considered typical. QOSP 2 of Sequential Finger touching is also a Neurological Soft Sign and is seen to be developing till the age of 5-6 years. The performance on this test expects the child to have smooth and sequential individual finger movement without visual input when the child attempts to touch each of his fingers with the thumb. It was seen that the response improved in the younger group when visual input was allowed. QOSP 6 
Table 2: Percentage of Children Scoring Grade 1 Response on QOSP

\begin{tabular}{|c|c|c|c|c|c|c|c|}
\hline \multirow[b]{2}{*}{ No. } & \multirow[b]{2}{*}{ Parameter } & \multicolumn{6}{|c|}{ Response of Grade 1} \\
\hline & & \multicolumn{2}{|c|}{$\begin{array}{c}\text { Group } 1 \\
\text { 3-5 Years }\end{array}$} & \multicolumn{2}{|c|}{$\begin{array}{c}\text { Group } 2 \\
>5 \text { up to } 7 \text { Years }\end{array}$} & \multicolumn{2}{|c|}{$\begin{array}{l}\text { Group } 3 \\
\text { 3-7 Years }\end{array}$} \\
\hline 1 & Diadokokinesis & 120 & 79.5 & 118 & 78 & 238 & 78.8 \\
\hline 3 & Finger Nose Test & 140 & 92.7 & 109 & 72.2 & 249 & 82.5 \\
\hline 4 & Anti Gravity Flexion & 87 & 57.6 & 121 & 80.1 & 208 & 68.9 \\
\hline 5 & Schilder's Arm Extension & 101 & 66.9 & 101 & 66.9 & 202 & 66.9 \\
\hline 6 & Anti Gravity Extension & 66 & 43.7 & 92 & 60.9 & 158 & 52.3 \\
\hline 10 & Gravitational Insecurity & 151 & 100 & 150 & 99.3 & 301 & 99.7 \\
\hline 11 & Projected Action Sequences & 121 & 80.1 & 100 & 66.2 & 221 & 73.2 \\
\hline 12 & Bilateral Motor Coordination & 95 & 62.9 & 97 & 64.2 & 192 & 63.6 \\
\hline 13 & Reaction to Vestibular Sensations & 144 & 95.4 & 131 & 86.8 & 275 & 91.1 \\
\hline 14 & Reaction to Tactile Sensations & 151 & 100 & 132 & 87.4 & 283 & 93.7 \\
\hline 15 & Free Play and Play Preferences & 114 & 75.5 & 91 & 60.7 & 205 & 68.1 \\
\hline 16 & Praxis & 120 & 79.5 & 101 & 66.9 & 221 & 73.2 \\
\hline 17 & Consciously Controlled Eye Movements & 112 & 74.2 & 126 & 83.4 & 238 & 78.8 \\
\hline
\end{tabular}

of Prone Extension expects the child to assume and maintain or hold the pivot prone position of the body with torso and thighs off the ground. While it was seen that Group 2 of older children could hold the position for longer time, younger children in Group 1 could not do so. Hence the maintaining time for Group 1 is up to 20 seconds whereas for Group 2 it can be up to 60 seconds. The sub items of the QOSP also showed slight variations according to the age and were considered to be expected response in contrast to the expected response mentioned in the literature. These included the response to QOSP 14 of Reaction to Tactile Sensation where the younger children were expected to identify the texture of the object and not actually recognize it whereas the older children could recognize and name the object in absence of visual input.

It was also observed that QOSP has age related significance. Table 3 shows the parameters that had significant correlation with age. This finding points to support the past research that mentions maturity of the brain with age [26-28]. As the sensory systems physiologically, anatomically and experientially mature and develop with age refinement in the response is observed.

QOSP that signify this finding are $1,2,3,4,6,7,11$ 16. They are the parameters that expect good coordination, postural control, planning and performing skills. QOSP 1, 2 and 3 are also a part of NSS. While studies by Bagchi (1996) and Gasser (2012) have suggested NSS as markers of neurological development and maturity, studies by Uslu (2007) and Patankar (2012) have suggested inclusion of NSS in evaluation of ADHD and Learning disability [29]. These findings strongly support the studies in literature done to support the role of age with respect to motor accuracy and speed of movement, developmental variations and maturity in play and refinement of bilateral motor coordination skills. Thus QOSP parameters $1,2,3,4,6,7,11,12,13,14,15$ and 16 that show difference with age can be considered clinically important to identify developmental lags in sensory processing. 
Table 3: Age Related Significance of QOSP

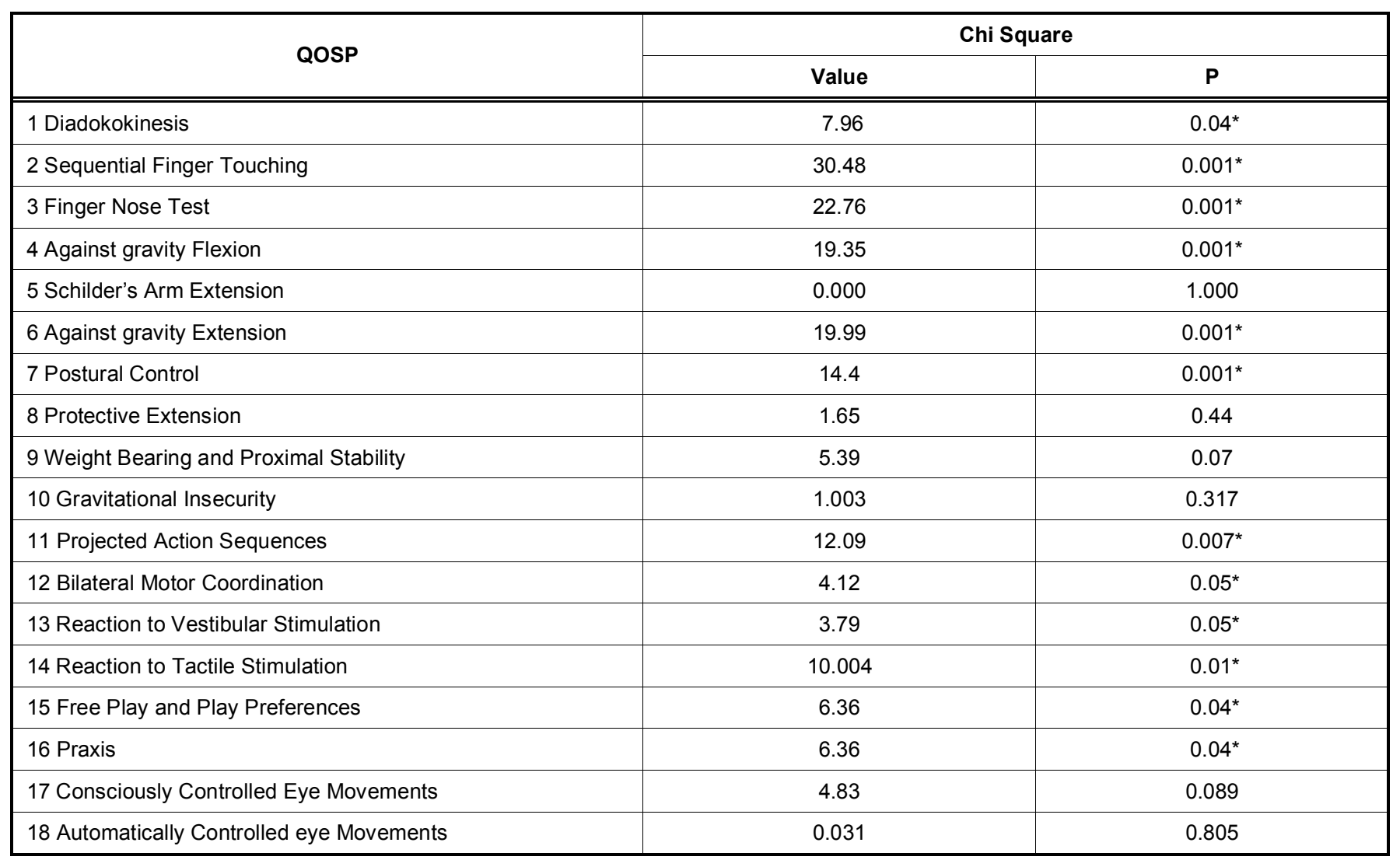

*Significant statistically $p<0.001$.

However it was observed that QOSP $5,8,9,10,17$ and 18 did not show any age related significance. QOSP 5 and 9 depend on the tonal characteristic of proprioceptive sensation which does not seem to alter with age whereas QOSP 8 is an innate reflex present since birth that shows no refinement with age. QOSP 10 is suggestive of modulatory affectation of vestibular processing and hence has no relevance with age. QOSP 17 and 18 are the visuo-vestibular parameters. Visuo-vestibular system is active right from very early stages of life and hence its basic parameters show subtle refinement with age that is statistically insignificant.

The correlations (Tables 4, 5) of Somatosensory Processing Parameters (QOSP 1, 2, 3) and Vestibuloproprioceptive Processing Parameters (QOSP 5,7,9, 13) highlight the role of proprioception in joint position, reaching of movement and motor speed. This also justifies the modulatory ability of proprioception in regulating tone, limb and trunk movements while maintaining balance. It suggests that modulatory dysfunction of proprioception may result in proprioceptive insecurity. The correlation of Vestibuloproprioceptive parameters and Visuo-vestibular parameters suggest and support the view of Balslev (2012) that the proprioceptive signals from extra ocular muscles modulate visual attention [30].

The correlation of Vestibulo-proprioceptive parameters (QOSP $4,6,7,8,10,11,12,13$ ) signify the role of vestibular sensations in maintaining the body and body segments in space while anticipating head movements. Many researchers are of the view that vestibular processing retains body balance and postural control with respect to movement and gravity. Fischer et al. (1988) suggest that vestibuloproprioceptive processing can be observed in body maintaining equilibrium and Ling Chin Kai et al. (2012) found association of postural movements with bilateral motor integration in vestibular processing $[31,32]$. The correlations of QOSP 7, 12 support these views. The action sequences in QOSP 11 that require maintaining balance, body position with coordination reciprocal to change in head and eye movements signify the role of vestibular processing. The correlations suggest that affected vestibular processing may result in modulatory disorder i.e. Gravitational Insecurity (QOSP 10 correlation with QOSP 7, 11 and 13). It is seen from Tables 4 and 5 that QOSP 8 which is an innate reflex 
Table 4: Correlations of QOSP 1- 9

\begin{tabular}{|c|c|c|c|c|c|c|c|c|c|}
\hline & \multicolumn{9}{|c|}{ Spearman's Rho } \\
\hline & QOSP 1 & QOSP 2 & QOSP 3 & QOSP 4 & QOSP 5 & QOSP 6 & QOSP 7 & QOSP 8 & QOSP 9 \\
\hline \multicolumn{10}{|l|}{ Parameter } \\
\hline QOSP 1 & 1.000 & $.229^{* *}$ & $.332^{* *}$ & .045 & .101 & .070 & $.139^{*}$ & .107 & $.154^{* *}$ \\
\hline QOSP 2 & $.229^{* *}$ & 1.000 & .029 & $.219^{* *}$ & .058 & $.204^{* *}$ & .093 & .091 & .063 \\
\hline QOSP 3 & $.332^{* *}$ & .029 & 1.000 & -.052 & .078 & -.001 & $.235^{* *}$ & $.128^{*}$ & .059 \\
\hline QOSP 5 & .101 & .058 & .078 & $.123^{*}$ & 1.000 & $.193^{* *}$ & $.357^{\star *}$ & .109 & $.232^{\star *}$ \\
\hline QOSP 6 & .070 & $204^{* *}$ & -.001 & $.345^{* *}$ & $.193^{* *}$ & 1.000 & $.159^{* *}$ & .107 & .108 \\
\hline QOSP 7 & $.139^{*}$ & .093 & $.235^{* *}$ & $.157^{* *}$ & $.357^{* *}$ & $.159^{* *}$ & 1.000 & $.265^{* *}$ & $.309^{* *}$ \\
\hline QOSP 8 & .107 & .091 & $.128^{*}$ & .092 & .109 & .107 & $.265^{* *}$ & 1.000 & .103 \\
\hline QOSP 9 & $.154^{\star *}$ & .063 & .059 & .084 & $.232^{* *}$ & .108 & $.309^{* *}$ & .103 & 1.000 \\
\hline QOSP 13 & $.195^{* *}$ & .105 & $.183^{* *}$ & $.144^{*}$ & $.174^{* *}$ & $.146^{*}$ & $.635^{* *}$ & $.411^{* *}$ & $.250^{* *}$ \\
\hline QOSP 14 & .092 & -.035 & $.134^{*}$ & .010 & .078 & .034 & $.122^{*}$ & $.155^{* *}$ & .063 \\
\hline QOSP 15 & $.220^{\star *}$ & $.268^{* *}$ & $.122^{*}$ & .112 & $.177^{* *}$ & $.234^{* *}$ & $.261^{* *}$ & .076 & $.137^{*}$ \\
\hline QOSP 16 & $.313^{* *}$ & $.237^{* *}$ & $.255^{* *}$ & $.153^{* *}$ & $.135^{*}$ & $.190^{* *}$ & $.323^{* *}$ & .102 & $.206^{* *}$ \\
\hline QOSP 17 & $.193^{* *}$ & $.320^{* *}$ & .058 & .091 & $.188^{* *}$ & $.237^{* \star}$ & .106 & .067 & $.146^{*}$ \\
\hline QOSP 18 & $.152^{* *}$ & $.194^{\star *}$ & .092 & $.119^{*}$ & $.124^{*}$ & $.169^{* *}$ & .111 & .059 & .095 \\
\hline
\end{tabular}

*Significant $p<0.01,{ }^{* *}$ significant $p<0.001$.

Table 5: Correlations of QOSP 10 -18

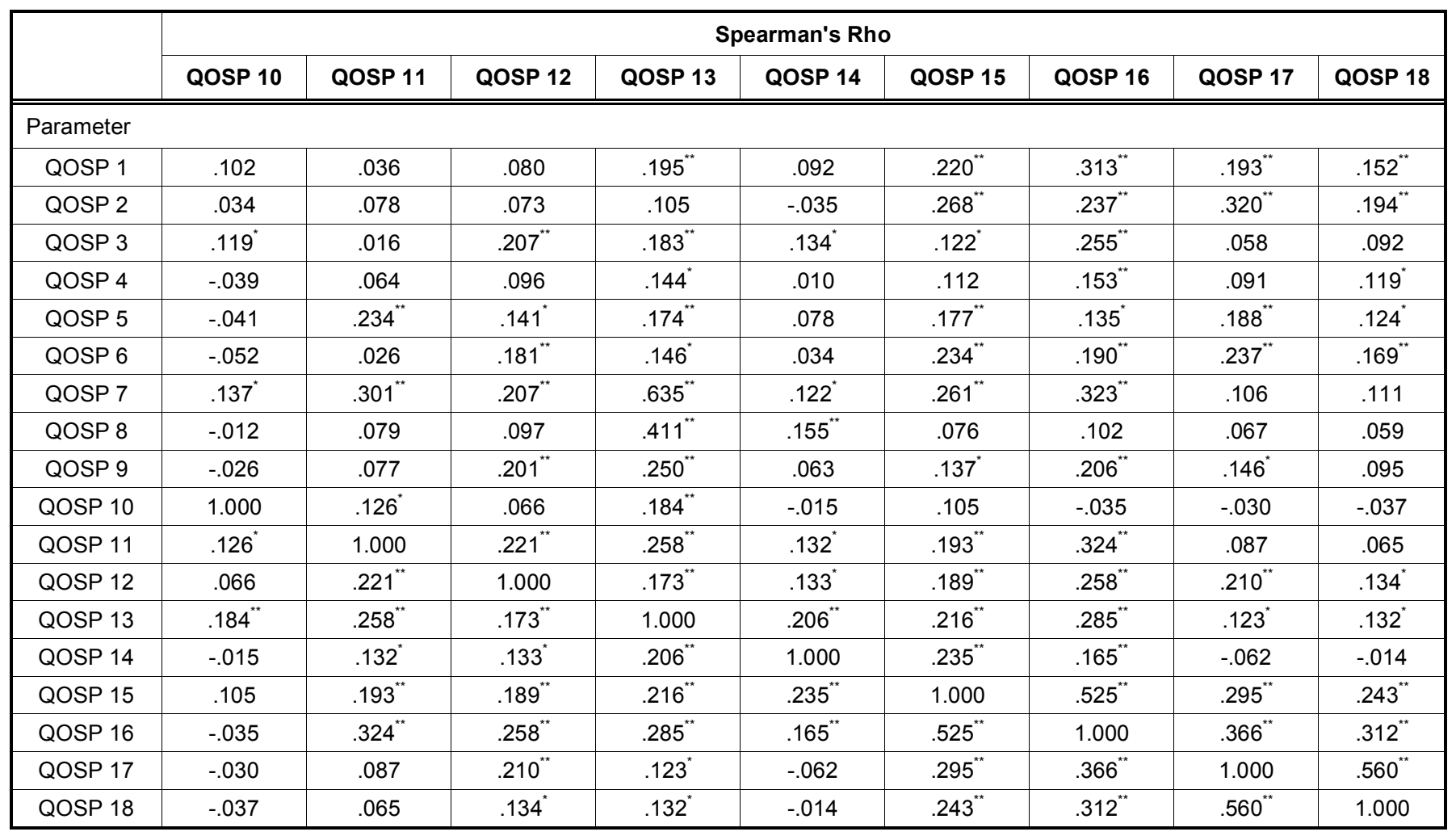

${ }^{*}$ Significant $p<0.01,{ }^{* *}$ significant $p<0.001$. 
and responds to movement and gravity changes by exhibiting protective extension of upper limbs and neck does not correlate with QOSP 13 of Gravitational Insecurity $(\mathrm{Gl})$. It hence suggests that children with affected protective extension reflex need not have $\mathrm{GI}$. But a child with GI may be observed to exhibit excessive fear when asked to be on ball or forego his contact with ground with balance challenging postures.

QOSP 14 evaluates the stereognostic ability of the child. This ability conveys information about registration and haptic perception of touch. Haptic perception helps in identifying objects and their features alongwith the spatial manipulations and explorations done by muscles and joints while handling them. Hence QOSP 14 which evaluates the somatosensory system is thought to majorly contribute to somato praxis that involves planning and constructing theme of the activity to be done [33]. The correlation of QOSP 14 with QOSP 3, 7, 8, 11, 15 and 16 support its somatosensory and vestibulo proprioceptive connections.

QOSP 15 observes for the playfulness of the child in light of sensory processing. A child uses his somato sensory processing when he decides about the movements to be used, plans for the steps in his play, interacts with peers, feels and remembers the haptic dimensions of the play objects. His physical activity, posture and postural adjustments depend on his vestibulo- proprioceptive processing while visual interaction and integration on visual processing. The therapeutic relationship between play and sensory processing was also explained by Lindquist et al. (1982) [34]. The parameters of QOSP 15 procure sensory processing information in children who comprehend verbal commands and otherwise, where other QOSP may not be comprehended. The correlation of this QOSP with QOSP 1, 2, 3, 5, 6, 7, 9, $11,12,13,14,16,17$ and 18 strongly support these views.

QOSP 16 of Praxis observes the child for his performance on activities requiring eye- hand coordination (motor), crossing midline of the body, body awareness, sequencing his activities and using preferred hand. These activities involve bilateral integration and sequencing along with good ideation (Bundy, 2002).

This observation therefore informs about visual, vestibulo-proprioceptive and somato sensory processing. Its correlation with QOSP 1, 2, 3, 4, 5, 6,7, $9,11,12,13,14,15,17$ and 18 support the theoretical construct of praxis as discussed by Ayres (1979) and Bundy (2002) [35].

Thus a child shows a good praxis as an end result of good motor speed, coordination and accuracy as observed on QOSP 1, 2 and 3, maturity of his nervous system observed on QOSP 2, good postural tone observed on QOSP 4, 5 and 6, appropriate background postural adjustments as observed on QOSP 7 and 13, effective proximal (girdle) stability that allows for hand mobility observed on QOSP 5 and 9 and his bilateral motor coordination and ability to plan strategies as observed on QOSP 12 and 13. The correlation of this QOSP with QOSP 17 and 18 supports the research of Gubbay (1979) and Henderson and Hall (1982) that suggests vision plays an important role in praxis [36, 37].

It is seen that QOSP 8 and 10 do not correlate with both QOSP 15 and 16 in the study. It may be inferred that as play is the personal preference of the child that is not threatening, he adapts it to his sensory perception. Hence it may not necessarily inform about the gravitational insecurity and the innate protective reaction of the child.

Durocher (2012), in his explanation of the optokinetic system, states that it involves interaction of vestibular system with visual system to detect head and body motion as well as eye movement [38]. This theoretical construct is clinically evaluated by QOSP 17 and 18 where visual focus and coordination is observed during head movement and eye movements. The proprioceptive and vestibular collaboration in visual information to perceive self motion and body awareness as studied by Butler et al. (2011) and Hanes-Douglas (2012) support the clinical evidence given through correlation of QOSP 5,6,9,12,13 with QOSP 17 and 18 [39, 40]. Milner \& Goodale (1993) and Mountcastle (1995) have suggested the role of visual guidance of locomotion in the environment or space through the pattern of visual stimulation on the retina called optic flow [41, 42]. Bertenthal \& Cliffton (1998) and Lee \& Aronson (1974) researched that younger children use the optic flow to control their posture $[43,44]$. Although this was found in infants, the present study supports this view in children till about 5 years of age through the correlation observed between QOSP 17 and 18 and all the QOSP of VPP in Group 1. Kellman \& Banks (1998) studied that older children inhibit postural response better. They proposed that as the child grows and develops his muscle tone and better strategies of balance control he seems to 
compensate for the optic flow [45]. This supports the less correlations observed between the vestibular balance observations of QOSP and QOSP 17 and 18 in Group 2.

\section{REFERENCE RANGE OF THE QOSP}

In absence of any gold standard to compare the tool with the reference range for the QOSP total score was determined. The use of a reference range or reference interval in health related fields has been advocated to usually describe the variations of a measurement or value in healthy individuals. It is a basis for a health professional to interpret a set of results for a particular individual [46-48]. Hence scores lesser than the lower limit of the reference range can be considered strongly indicative for an underlying disease or condition as a cause.

It can be seen from the Table 6 that the lower limit of the reference range for QOSP is $22-40$ for the children in Group 1 and 23 - 40 for the children in Group 2. The reference range for pooled children is also $23-40$ suggesting 23 as the lower limit.

Considering the lower limit of the reference range for QOSP, it was seen that about 3\% of the children in all groups lie below the lower limit 22 for Group1 and 23 for Group 2 and Pooled group. It was also observed that $78 \%(n=186)$ children in the age group of $3-7$ years scored between 32- 40 on QOSP. As the difference in the number of boys and girls with lower scores was negligible the study is not conclusive about role of gender in sensory processing. The study was also inconclusive about the role of economic status in sensory processing supporting the view of Bowman and Wallace (1990) [49].

The school based version of SPM showed that the $3 \%(n=8)$ children who had scored lower than the reference suggested definite dysfunctions in SP. This finding supported the view that QOSP could be used with their reference range to evaluate SP difficulties. $20 \%(n=58)$ of the children suggested probable SP dysfunctions in at least one functional area of SP on SPM. When the SPM results were studied in light of reference range for QOSP, it was seen that the children who were categorized as those having probable dysfunctions because of their observed behaviors did not score less than the lower reference limit of QOSP. They were scoring between 24 and 31 on the total score and could not be said to suggest definite SP dysfunctions. Nevertheless they failed to have expected scores in the parameters where majority had done well. This would definitely mean that these children should be closely monitored for specific sensory system processing difficulties so that they can perform optimally.

Thus the score of 24- 28 may be considered as an indicator of atypical function in some areas of sensory processing. The findings of the study once again support the theoretical constructs of Sensory Processing and suggest that questionnaires evaluating SP behaviors should be supported by clinical assessment.

For the purpose data triangulation and to evaluate the applicability of the resource tool, a comorbid sample of 38 children with variable diagnoses was evaluated on the QOSP. QOSP scores obtained in age matched children (Mean 5.3 years, SD \pm 1.15 ) with comorbid conditions that included Attention Deficit Hyperactivity Disorder (ADHD), Autism, Pervasive Developmental Disorder (PDD), Developmental Coordination Disorder (DCD) along with Learning Disabilities (LD) and other behavioral abnormalities. These children had also been reported to have behaviors resembling SP dysfunctions. It was seen that the children with PDD, Developmental Disorders, Autism and combined diagnoses were scoring less than 20 on QOSP whereas those with ADHD, LD, and Behavioral Disorders etc were scoring between 21 to 24. This may suggest that the children with diagnoses of PDD, Autism were affected with higher intensity of Sensory Processing difficulties than the others. When the scores were analyzed using Receiver Operating Characteristic (ROC) to arrive at a cut off of QOSP in co-morbid conditions and it was found to be score of 24. This score is very near to the lower limit of reference range observed. QOSP is found to be sensitive and specific to assess SP difficulties in co-

Table 6: Reference Range of QOSP

\begin{tabular}{|c|c|c|c|}
\hline $\mathbf{9 0 \%} \mathbf{~ C l}$ & Group 1 (3-5 Years) & Group 2 (5-7 Years) & Pooled Group (3-7 Years) \\
\hline \hline Lower limit & 22 & 23 & 23 \\
\hline Upper limit & 40 & 40 & 40 \\
\hline
\end{tabular}


morbid conditions. The study supports the findings of Kinnealey, 1997; Huecker, 1998; Mangeot et al., 2001; Lane et al., 2010; Koziol, Budding, 2012, for such comorbidities to have affected sensory processing [5053].

\section{CONCLUSION}

The study attempts to bridge the gap of understanding the faint line of demarcation between typical and atypical sensory processing pertaining to Indian population. It suggests that Sensory Processing matures and develops with age. It provides a valid resource not only to evaluate and understand SP in younger children but also to screen possible dysfunctions in time. It has established a guideline in the form of QOSP to understand SP in light of theoretical constructs. The study also highlights that parental or school observations can be more authentic when supported with clinical observations like QOSP. The evaluations based on QOSP would give rehabilitation personnel working in this area a definite idea of the deficient sensory processing system so that a more organized remediation protocol can be set and measurable goals can be achieved. It opens future research avenues for standardization in other populations and can be used to understand the impact of different factors affecting sensory processing.

\section{REFERENCES}

[1] Ayres AJ. Deficits in sensory integration in educationally handicapped children. J Learn Disabil 1969; 2: 160-8. http://dx.doi.org/10.1177/002221946900200307

[2] Lane S. Structure and Function of the Sensory Systems. In: Bundy A, Lane S, Murray E. Sensory integration Theory and Practice. $2^{\text {nd }}$ Edition. Philadelphia. F A Davis and Company 2002; p. 35-67.

[3] Roley S, Blanche E, Schaaf R. Understanding the nature of Sensory Integration with Diverse Populations. Pro-ed Publishers. 2001.

[4] Luna R, Hernández A, Brody CD, Romo R. Neural codes for perceptual discrimination in primary sensory cortex. Nat Neurosci 2005; 8: 1210-9. http://dx.doi.org/10.1038/nn1513

[5] Kringelbach $M$. The human orbitofrontal cortex: linking reward to hedonic experience. Nat Rev Neurosci 2005; 6: 691-702.

http://dx.doi.org/10.1038/nrn1747

[6] Shriber L. (Retrieved 2013) Sensory Integration. In: JH Stone, M Blouin, editors. International Encyclopedia of Rehabilitation. URL: http://cirrie.buffalo.edu/encyclopedia/ en/article/361/

[7] Lane S, Reynolds S, Thacker L. Sensory over-responsivity and ADHD: differentiating using electrodermal responses, cortisol, and anxiety. Front Integr Neurosci 2010; 4: 8. http://dx.doi.org/10.3389/fnint.2010.00008

[8] Benson J, Meghan N, Stern P. How does a child with Sensory Processing problems play? Internet J Allied Health Sci Pract 2006; 4: 1-7.
[9]

Owen J, Marco E, Desai S, et al. Abnormal white matter microstructure in children with sensory processing disorders. Neuroimage Clin 2013; 2: 844-53. http://dx.doi.org/10.1016/j.nicl.2013.06.009

[10] Ahn RR, Miller LJ, Milberger S, McIntosh DN. Prevalence of parents' perceptions of sensory processing disorders among kindergarten children. Am J Occup Ther 2004; 58: 287-93. http://dx.doi.org/10.5014/ajot.58.3.287

[11] Ben-Sasson A, Carter AS, Briggs-Gowan MJ. Sensory overresponsivity in elementary school: prevalence and socialemotional correlates. J Abnor Child Psychol 2009; 37: 70516. http://dx.doi.org/10.1007/s10802-008-9295-8

[12] Miller -Kuhaneck H, Henry D, Glennon TJ, Mu K. Development of the sensory processing measure - school form: initial studies of reliability and validity. Am J Occup Ther 2007; 61: 170-5. http://dx.doi.org/10.5014/ajot.61.2.170

[13] Dobbins $M$, Sunder T, Soltys S. Non-verbal learning disabilities and sensory processing disorders. Psychiatric Times 2007; 24.

[14] Schoen S, Miller L, Brett- Green B, Neilsen D. Physiological and behavioral differences in sensory processing: a comparison of children with autism spectrum disorder and sensory modulation disorder. Front Integr Neurosci 2009; 3 : 29. http://dx.doi.org/10.3389/neuro.07.029.2009

[15] Blanche, E, Reinoso G. The use of clinical observations to evaluate proprioceptive and vestibular functions. OT Practice 2008; 13: CE1- 6.

[16] Bagchi D, Khanna R, Raju S. Prevalence of soft neurological signs: a study among indian school boys. Indian J Psychiatry 1996; 38: 196-200.

[17] Patankar VC, Sangle JP, Shah HR, Dave M, Kamath RM. Neurological soft signs in children with attention deficit hyperactivity disorder. Indian J Psychiatry 2012; 54: 159-65. http://dx.doi.org/10.4103/0019-5545.99540

[18] Bengoetxea H, Ortuzar N, Bulnes S, Rico-Barrio I, Lafuente JV, Argandoña EG. Enriched and deprived sensory experience induces structural changes and rewires connectivity during the postnatal development of the brain. Neural Plast 2012; 2012: 305693. http://dx.doi.org/10.1155/2012/305693

[19] Schanberg S, Field T. Sensory deprivation stress and supplemental stimulation in the rat pup and preterm human neonate. Child Dev 1987; 58: 1431-47. http://dx.doi.org/10.2307/1130683

[20] Provence S, Lipton RC. Infants in institutions: A comparison of their development with family-reared infants during the first year of life. New York: International Universities Press. 1962.

[21] Ptito M, Kupers R, Lomber S, Pietrini P. Sensory deprivation and brain plasticity. Neural Plast 2012; 2012: 810370. http://dx.doi.org/10.1155/2012/810370

[22] Benson J, Meghan N, Stern P. How does a child with sensory processing problems play? Internet J Allied Health Sci Pract 2006; 4: 1-7.

[23] Bundy A, Shia S, Qi L, Miller LJ. How does sensory processing dysfunction affect play? Am J Occup Ther 2007; 61: 201-8. http://dx.doi.org/10.5014/ajot.61.2.201

[24] Bailey CM. Learning through play and fantasy, EC 1297E, Corvallis, OR Oregon State University 2006.

[25] Griesemer D. The Neurologic Examination. In: Maria B. Current Management in Child Neurology 3rd Edition B C Decker Inc London 2005.

[26] Denckla MB. Development of speed in repetitive and successive finger movements in normal children. Dev Med Child Neurol 1973; 15: 635-45. http://dx.doi.org/10.1111/j.1469-8749.1973.tb05174.x 
[27] Gasser T, Rousson V, Caflisch J, Jenni O G. Development of motor speed and associated movements from 5 to 18 years. Dev Med Child Neurol 2010; 52: 256-63. http://dx.doi.org/10.1111/j.1469-8749.2009.03391.x

[28] Larson JC, Mostofsky SH, Goldberg MC, Cutting LE, Denckla MB, Mahone EM. Effects of gender and age on motor exam in typically developing children. Devel Neuropsychol 2007; 32: 543-62. http://dx.doi.org/10.1080/87565640701361013

[29] Uslu R, Kapci EG, Oztop D. Neurological soft signs in comorbid learning and attention deficit hyperactivity disorders. Turk J Pediatr 2007; 49: 263-9.

[30] Balslev D, Newman W, Knox PC. Extraocular muscle afferent signals modulate visual attention. Invest Ophthalmol Vis Sci 2012; 53: 7004-9. http://dx.doi.org/10.1167/iovs.12-10249

[31] Fischer AG, Wietlisbach SE, Wilbarger JL. Adult performance on three tests of equilibrium. Am J Occup Ther 1988; 42: 305.

http://dx.doi.org/10.5014/ajot.42.1.30

[32] Lin $\mathrm{CK}, \mathrm{Wu} \mathrm{HM}$, Lin $\mathrm{CH}$, et al. A small sample test of the factor structure of postural movement and bilateral motor integration using structural equation modeling. Percept Mot Skills 2012; 115: 544-57.

http://dx.doi.org/10.2466/25.03.10.PMS.115.5.544-557

[33] Gibson JJ. Observation on active touch. Psychol Rev 1962; 69: 477-91. http://dx.doi.org/10.1037/h0046962

[34] Lindquist JE, Mack W, Parham D. A synthesis of occupational behavior and sensory integration concepts in theory and practice, part 2: clinical applications. Am J Occup Ther 1982; 36: 433-7. http://dx.doi.org/10.5014/ajot.36.7.433

[35] Reeves GD. Disorders of Praxis. In: Bundy A, Lane S, Murray E. Sensory integration Theory and Practice. $2^{\text {nd }}$ Edition. Philadelphia. F A Davis and Company.2002. pg 7195.

[36] Gubbay SS. The clumsy child. In F. C. Rose (Ed.), Pediatric Neurology. London: Blackwell 1979.

[37] Henderson SE, Hall D. Concomitants of clumsiness in young school children. Dev Med Child Neurol 1982; 24: 448-60. http://dx.doi.org/10.1111/j.1469-8749.1982.tb13649.x

[38] Durocher Richard. Retrieved. Vision \& Learning- Optometric Physicians of Middle Tennesse. URL: http://www.rdeyes.com/vision-learning/. 2012

[39] Butler J, Campos JL, Bülthoff HH, Smith ST. The role of stereo vision in visual-vestibular integration. Seeing Perceiving 2011; 24: 453-70. http://dx.doi.org/10.1163/187847511X588070

[40] Hanes D. Mathematical requirements of visual-vestibular integration. J Math Biol 2012; 65: 1245-66. http://dx.doi.org/10.1007/s00285-011-0494-5

[41] Milner AD, Goodale MA. Visual pathways to perception and action. In T. P. Hicks, S. Molotchnikoff \& T. One (Eds.). The visually responsive neuron: From basic neurophysiology to behavior (pp.317- 337). New York. Elsevier Science. 1993.

[42] Mountcastle VB. The parietal system and some higher brain functions. Cereb Cortex 1995; 5: 377-90. http://dx.doi.org/10.1093/cercor/5.5.377

[43] Bertenthal BI, Clifton RK. Perception and action. In W Damon (Ed. In Chief), D. Kuhn \& R Seigler (Vol. Eds.) Handbook of Child psychology. $5^{\text {th }}$ Edition Vol.2. Cognition, Perception and Language. New York: John Wiley \& Sons. 1998.

[44] Lee DN, Aronson E. Visual proprioceptive control of standing in human infants. Percept Psychophys 1974; 15: 529-32. http://dx.doi.org/10.3758/BF03199297

[45] Kellman P, Banks M. Infant visual perception. In W. Damon (Ed. In Chief), D. Kuhn \& R Seigler (Vol. Eds.) Handbook of Child psychology. $5^{\text {th }}$ Edition Vol.2. Cognition, Perception and Language. New York: John Wiley \& Sons. 1998.

[46] Grasbeck R, Saris NE. Establishment and use of normal values. Scandinavian Journal of Clinical Laboratory Investigation. 1969; 110:62-3.

[47] Solberg HE. International Federation of Clinical Chemistry (IFCC), Scientific Committee, Clinical Section, Expert Panel on Theory of Reference Values, and International Committee for Standardization in Haematology (ICSH), Standing Committee on Reference Values. Approved Recommendation (1986) on the theory of reference values. Part 1. The concept of reference values. J Clin Chem Clin Biochem 1987; 25: 337-42.

[48] Bangert, Marshall W MA in FIBiol; Marshall, William Leonard. Clinical biochemistry: metabolic and clinical aspects. Philadelphia: Churchill Livingstone/Elsevier. 2008

[49] Bowman OJ, Wallace B. The in effects of socioeconomic status on hand size and strength, vestibular function, visuomotor integration, and praxis preschool children. Am J Occup Ther1990; 44: 610-21. http://dx.doi.org/10.5014/ajot.44.7.610

[50] Kinnealey M, Miller LJ. Sensory Integration/ Learning Disabilities. In: Eds H.L. Hopkins \& H. D. Smith, Willard and Spackman's Occupational Therapy. Philadelphia. J. B. Lippincott \& Co. $8^{\text {th }}$ Edition. 1993. Pg 474-89.

[51] Huecker GE, Kinnealey M. Prevalence of sensory integrative disorders in children with attention deficit hyperactivity disorder: a descriptive study. 1998; 2: 265-92.

[52] Mangeot SD, Miller LJ, Mclntosh DN, et al. Sensory modulation dysfunction in children with Attention deficit hyperactivity disorder. Dev Med Child Neurol 2001; 43: 399406. http://dx.doi.org/10.1017/S0012162201000743

[53] Koizol L, Budding D, Chidekel D. Sensory integration, sensory processing, and sensory modulation disorders: putative functional neuroanatomic underpinnings. Cerebellum 2011; 10: 770-92. http://dx.doi.org/10.1007/s12311-011-0288-8

\section{DOI: http://dx.doi.org/10.6000/2292-2598.2014.02.01.1}

(C) 2014 Moushami S. Kadkol; Licensee Lifescience Global.

This is an open access article licensed under the terms of the Creative Commons Attribution Non-Commercial License (http://creativecommons.org/licenses/by-nc/3.0/) which permits unrestricted, non-commercial use, distribution and reproduction in any medium, provided the work is properly cited. 